\title{
Cantos de máscaras no nordeste brasileiro e na África Central e do Oeste: pistas para uma análise comparativa
}

\author{
André C. Paula Bueno*
}

\begin{abstract}
BUENO, A.C.P. Cantos de máscaras no nordeste brasileiro e na África Central e do Oeste: pistas para uma análise comparativa. Revista do Museu de Arqueologia e Etnologia, São Paulo, 20: 381-391, 2010.
\end{abstract}

Resumo: Dados de lingua e dados de literatura oral são contrastados aqui, para enfocar cantos afro-brasileiros e africanos relacionados a personagens de máscara. Selecionei um canto de minha pesquisa de campo anterior no estado do Maranhão, um poema de Angola e um canto dogon do Mali. O primeiro vem em Português Brasileiro com palavra do quimbundo; o segundo vem em Português Angolano com palavras do quimbundo; o terceiro vem em dogon com frases da língua local de iniciação sigi-so. O empréstimo da palavra africana cazumba no Brasil é mostrado (do quimbundo kanzumbi). As coerências em significação e detalhes narrativos, de ambos os lados do Atlântico, são consistentes e evocam novos passos de comparação a realizar. A chave teórica do "monstruoso" e do "monitor" ou mestre iniciador, como utilizada por N. Sega Touré (em Baumgardt e Ugochukwu 2005), ajuda a estabelecer essa comparação e a ligar conceitos dos estudos de etnologia, línguística e literatura. E as notas explicativas sobre o caso brasileiro e seu contexto realçam a importância do bumba-boi maranhense e sua dinâmica de transmissão oral.

Palavras-chave: Cantos de máscara - Monstruoso - Bumba-meu-boi Cazumba - Afro-brasileiro - Quimbundo - Música de tradição oral - Dogon.

\section{Introdução}

To nordeste brasileiro, no estado do Maranhão (Mapa 1), ${ }^{1}$ designa-se com o nome de "cazumba" um personagem de máscara que expressa referências simbólicas de ancestralidade africana, nos grupos locais de Bumba-boi. ${ }^{2}$ São estes personagens, além do ritmo e padrão melódico, que caracterizam o estilo ou "sotaque" ${ }^{3}$ de boi $^{4}$ da Baixa- $\left({ }^{*}\right)$ Doutor em Literatura Brasileira com pós-doutorado em Etnolinguistica e Literatura Oral FFLCH-USP/DL - Grupo de Estudos de Linguas Africanas Universidade de São PauloGELA-USP, com bolsa FAPESP e estágio no LLACAN/ CNRS.<buenoacp9@gmail.com>, <buenoacp@usp.br>.
(1) A região da Baixada Maranhense, em foco, corresponde à planície noroeste do estado, que se estende da cidade de São Luís à fronteira com o estado do Pará. A Baixada Maranhense é a região do país que soma o maior número 
da, que engloba municipios e localidades de Viana, Matinha, Pindaré-mirim, São João Batista, Penalva... Na capital São Luís, os "cazumbas" ${ }^{5}$ aparecem justamente nos grupos que chegaram da Baixada Maranhense.

Realizei pesquisas de campo e transcrições dos textos cantados nessas danças em trabalhos anteriores, tese e publicação (Bueno 1999, 2001 e 2006).

Em Angola o termo similar "casumbi" é ocorrente na literatura e na poesia nacionalista que emergiu do contato português-quimbundo. ${ }^{6}$ O resultado de minhas pesquisas de campo no Brasil abre caminho para uma comparação produtiva com os dados angolanos. Abordo um poema angolano que fala do distanciamento entre o português escrito das cidades e as oralidades bantas do interior, e emprega o termo "casumbi". O aproveitamento de documentos vivos, gravados e transcritos, amplia o entendimento desses textos e de seus aportes literários.

Um paralelo africano aprofundado da significação mítico-social e poética das máscaras surge no contato com dados etnográficos dogon do Mali, nos ciclos de cantos de másca- ras transcritos em 1938 (Griaule) e 1989 (Dogon e Tembely).

As pistas para comparação, aqui, desenvolvem-se com apoio da chave teórica do "monstruoso", no domínio da literatura oral (cf. Sega Touré apud Baumgardt e Ugochukwu 2005). Realmente esses personagens se exprimem e se comportam, em contextos complementares, como figurações do "monstruoso" e do "monitor" ou mestre iniciador, categorias narrativas homólogas àquelas da semiótica greimasiana (Greimas 1982; Bueno 1999 e 2001). Os percursos narrativos do sujeito e do destinadormanipulador se diversificam de maneira coerente nesse quadro de oralidade africana e afro-brasileira que os trabalhos de etnólogos e linguistas permitem interpretar passo a passo.

Apresento aqui a fase inicial da comparação entre os textos orais e poéticos do Maranhão, de Angola e dos dogons do Mali. Em cada caso, registrei em campo e transcrevi (toada maranhense), re-transcrevi do português (V. Cruz in A.C.E.I. 1994) e de texto bilingue quimbundo-português (Chatelain 1964 [1894]) ou traduzi de texto bilingue dogon-francês (Griaule 1983 [1938], Dogon, G.R.C. 1989). de comunidades rurais afro-brasileiras, os quilombos: são ali cerca de 300 comunidades.

(2) A dança ou "brincadeira de boi", ("bumba-boi" ou "bumba-meu-boi") é uma tradição pan-brasileira (cf. Bueno 2001). No estado do Maranhão é praticada por centenas de grupos locais, compostos de cantores, percussionistas e dançantes que interpretam personagens tradicionais. A identidade desses grupos de boi varia em função das áreas do Maranhão. Para designar essa identidade (estilo melódico-percussivo, poético e narrativo) segundo a região de origem dos grupos, o termo vernáculo "sotaque" é utilizado em contexto. Falam assim dos bois de Guimarães, bois da Baixada, os de Cururupu e os da Ilha (da capital São Luis) por seu "sotaque" demarcado. Em 1990 se encontravam, por todo o estado, duzentos grupos de boi, oficialmente registrados como associações de bairro (cf. Golder 1991). Em geral no Brasil esta "brincadeira" é considerada uma prática folclórica, mas no Maranhão é vista como dança local de negros e caboclos (aqui mestiços afro-amerindios).

(3) Os termos "sotaque", "brincadeira" e "toada" são variantes dialetais orais do Português Brasileiro (PB). O uso desses termos é extensivo no contexto dos grupos de Boi e Tambor-de-Crioula, danças locais do Maranhão, e por vezes no contexto mais amplo das comunidades rurais afro-brasileiras. Na toada analisada em seguida, o termo Roxa (literalmente de cor violeta) é também atestado como apelido de mulher negra em cantos e falas de comunidades culturais urbanas: os grupos de capoeira, as escolas de samba e as casas de culto afro-brasileiro de São Luis, Recife, Salvador, Rio de Janeiro, Belo Horizonte e São Paulo. Falei de Português Afro-Brasileiro PAB, para Roxa e outros termos orais mais disseminados, no desenvolvimento de estudos do projeto "A participação das linguas africanas na constituição do Português Brasileiro" (Margarida Petter/Bernard Caron, CAPES-COFECUB). (4) A encenação do boi, personagem central da dança, é materializada também através de uma máscara. É uma máscara corporal em madeira e fibra coberta de veludo negro, ricamente bordado e munido de uma saia. Só os pés do manipulador-dançante são visiveis. $\mathrm{O}$ trabalho de bordado, feito por especialistas locais da Baixada, Cururupu, Guimarães e Ilha, é renovado a cada ano, com o novo nome do boi. O bordado da cabeça e dos olhos é figurativo, e o corpo renova motivos religiosos e culturais locais. Só os chifres são naturais, e a figura reproduz o tamanho de um novilho. Os bumba-meu-bois de Pernambuco e Bahia utilizam, para a máscara corporal, crânio e chifres de boi adulto e corpo de madeira e fibras do tamanho de um touro, resultando mais peso e menos mobilidade. 
São três os textos comparados aqui: uma toada de boi maranhense de Abel Teixeira, ${ }^{7} \mathrm{o}$ cazumba do Boi de Apolônio ("No centro de Zé Doca"); um poema angolano de Viriato da Cruz ("Serão de menino"); e um canto de máscara dogon de suspensão de luto ("Girubanu-go ninnyia wom" - "Tive medo do aspecto temivel", da aldeia de Pelu no Mali).

É no campo da literatura oral, mais conhecido e ampliado com as descrições das linguas africanas, e com a chave teórica do "monstruoso" que a comparação se torna possivel.

\section{Toada maranhense de "Abel Cazumba"} (Abel Teixeira, Bumba-boi de Apolônio da Floresta, São Luis-MA 2002).

Registrado no CD Bumba-meu-boi da Floresta, de 2002.

No centro de Zé Doca, oô

Tem uma onça e quando ela esturra

O povo da cidade tem medo (BIS)

Mandei chamar Zé de Roxa

Ele mora na Pedreira

(5) Os detalhes das máscaras ("caretas" no uso vernáculo) de cazumba e em particular os acessórios de quadril e saia são comparáveis àqueles das máscaras Geledés dos nagô-iorubá (Benim-Nigéria). Quanto ao nome cazumba, o termo "casumbi" é corrente em Angola (O. Ribas 1994 estima ser deformação de kanzumbi). Com efeito, as duas zonas de origem principal dos afro-brasileiros são o Congo-Angola (cerca de 1550 a 1880) e o Benim/Nigéria (cerca de 1750 a 1850). Existem duas publicações brasileiras sobre o cazumba do Maranhão, no Rio de Janeiro: um catálogo de exposição (Lody 1999) e um livro fotográfico (Mazzillo 2005). Os cazumbas formam, com adultos e jovens mascarados e vestidos, um grupo que dança em torno da máscara boi. Eles inspiram mistério e suscitam interesse: será que dançam para proteger ou para capturar o boi de veludo bordado? Os brincantes-dançantes de cazumba se encontram ocasionalmente a partir do mês de maio, para preparar as "caretas", "fardas" e acessórios, mas sem as mostrarem aos outros colegas. É apenas no "ensaio redondo" dos bois, no sábado próximo do Santo Antonio (13 de junho), ou do "batizado do boi" na noite de São João (23 para 24 de junho), que eles revelam as máscaras e toadas do ano. São então sete noites de festa entre o $23 \mathrm{e}$ o 29 de junho, dia de São Pedro. Nesses dias os
Pra trazer cachorra dele

Se essa onça esturra de novo, nós vamo atrás dela

Ô onça, tu não vai me comer.

A temática da onça é presente em toadas cantadas nos Bumba-bois maranhenses, mas não é frequente. No entanto, para Seu Abel Teixeira é um mote bem vivo, e ele tem feito toadas sobre aparecimento de onça já há vários anos. Abel reside em São Luís, mas veio do interior do Maranhão, da área rural do municipio de Viana, junto ao rio Pindaré na Baixada Maranhense (Mapa 1). Até 1978, quando se mudou para São Luís, ainda havia histórias reais de onças nesse interior, e quando se aproximavam de povoados por dias consecutivos, era preciso caçálas. "Zé Doca" é o nome de um dos povoados rurais de Viana-MA, e a toada retrata essa situação de presença de onça e audição de seu urro ou "esturro". Quando isso sucede, fala-se de onça velha cuja caça faltou e agora se aproxima de gado, galinhas ou mesmo habitações humanas, farejando restos. Diz-se que então é preciso caçála, ou certamente atacará a criação.

Por sua vez "Zé de Roxa", na toada o personagem dono da cachorra de caça, tem esse nome por

brincantes de cazumba, de Pai Francisco (Bueno 2001 e 2006) e de onça convivem juntos. E é habitualmente gente do interior que vem fazer esses três papéis de mascarados, com o modo de linguagem e sátiras que lhes são próprios.

(6) cazumbi se atesta como empréstimo quimbundo (Angola) no português brasileiro. Observa-se no Brasil o desuso do termo e o uso da forma zumbi, e a ressignificação maranhense, no contexto dos grupos do Bumba-boi. A ressemantização de cazumba pode ser interpretada como empréstimo cifrado (cf. Moñino 1991) e “identitário" (cf. Moñino 2006).

(7) Abel Teixeira é chamado de Abel cazumba porque ele dança e fabrica as máscaras. Em 1978 ele se mudou para São Luís convidado por Apolônio Melonio, fundador do Boi da Floresta, para ensinar as ações do personagem e a confecção das máscaras de cazumba. Nos anos 70 igualmente, Herbet Alves, o Betinho do Boi da Fé-emDeus, foi convidado por Terezinha Jansen para interpretar o Pai Francisco, personagem tradicional de máscara que consegue roubar o boi. Esses dois homens do interior dão exemplo particular de fixação na capital a partir de seus conhecimentos da linguagem narrativa do Bumba-boi. E a "brincadeira" adquire novo valor de trabalho eventual, num dos Estados mais pobres do Brasil. 


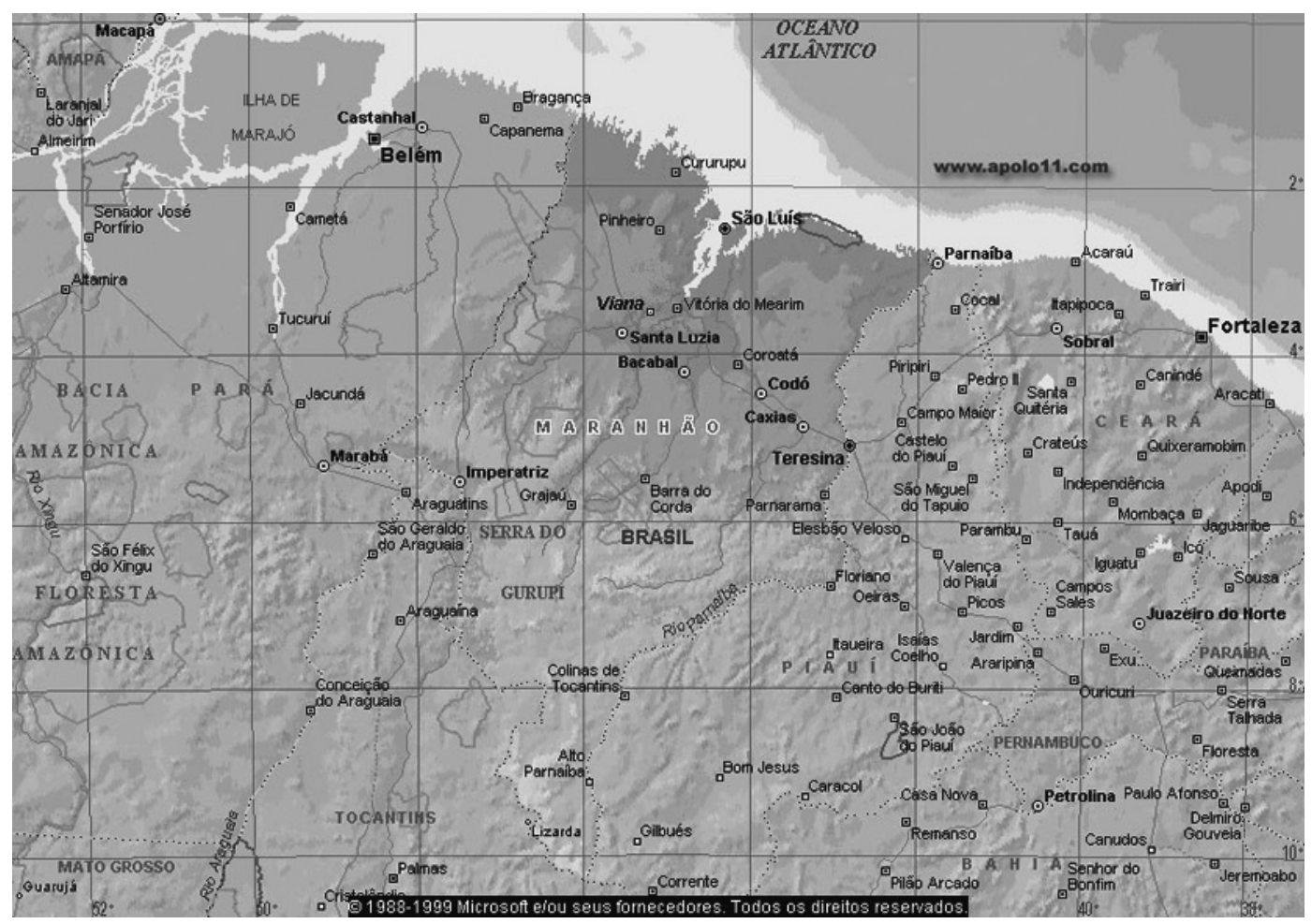

Mapa 1. O município de Viana, Maranhão, onde se localiza o povoado Zé Doca da toada cantada.

ser filho ou companheiro de senhora apelidada de Roxa. É frequente esse apelido para moças e senhoras negras de tom de pele bem pigmentado.

Abel Teixeira é conhecido como Abel Cazumba porque fabrica artesanalmente as "caretas" e "queixos" de cazumba - ou cazumbá - e ainda atua dançando caracterizado. Os cazumbas compõem um grupo, com adultos e jovens de máscara e farda costurada de saia longa, que vão dançando para longe e para perto do Boi da "brincadeira", despertando interesse e mistério: irão proteger ou roubar aquele novilho de veludo bordado? São personagens caracteristicos dos Bumba-bois da Baixada maranhense.

O fato de Seu Abel compor e cantar essas toadas com onças pode ser emparelhado com sua atuação como Cazumba do Bumba-meu-boi, articulando dois indices que interpreto como traços africanos nessas duas atividades. Na África, as máscaras de muitas tradições locais recriam representações de animais metamorfoseados, bases para a tensão narrativa que se estabelece em contos e outros gêneros orais da iniciação e aprendizagem de afazeres adultos. Se na toada maranhense aparece a onça, em diversos contos orais africanos manifesta-se o leão, e particularmente o espírito do leão, cujo confronto perigoso levará ao estágio de pessoa adulta, seja entre personagens, seja para a perfórmance ritual dos jovens engajados na iniciação. É o que explica a senegalesa N. Sega Touré na obra coletiva Approches littéraires de l'oralité africaine (Abordagens literárias da oralidade africana), de 2005, que enfocarei. E além dos contos wolof apontados por ela, narrativas fula e bambara do Mali, ou ainda shona do Zimbabwe do Niger ao Congo - trazem o leão como personagem fundamental. Animal feroz ou monstro, a máscara em ação dança e atualiza o mito e o conto, engajando as pessoas numa vivência de aprendizagem presencial.

É importante lembrar aqui que existe a onça personagem, de máscara e indumentária, em alguns desses mesmos Bumba-bois da Baixada Maranhense que apresentam os personagens Cazumbas. E assim essas pessoas, "brincantes" de máscara de Cazumba e de onça dentro dos 
grupos de Boi, agrupam-se com cumplicidade e auxilios mútuos, intercambiando papéis e novidades narrativas, ano após ano. Portanto, a toada cantada remete, sim, às histórias de caçada de onça, mas enuncia, no aqui e agora da "brincadeira", a presença narrada da onça e de seu portador na cena, com a máscara.

A comparação que proponho a partir deste ponto, entre registros de oralidades afrobrasileiras e africanas, aproveita indices de lingua e cultura ancestral que seguem vivos nos dois lados do Atlântico, inspirando a novas abordagens de pesquisa e ensino.

Sobre estes ritos africanos de iniciação, seus métodos de transmissão engajada de conhecimentos, nas tradições locais, oferecem modelos culturais da oralidade que precisam ser entendidos. Para além da dimensão antropológica, apontam princípios-base voltados à aprendizagem coletivizada, comparáveis a muitas situações contemporâneas de escolarização nas cidades.

E finalmente as máscaras, com suas literaturas orais associadas, podem ser vistas como ferramentas do mito, por entrarem em ação narrativa, em performance (Fotos 1a, 1b, 1c).

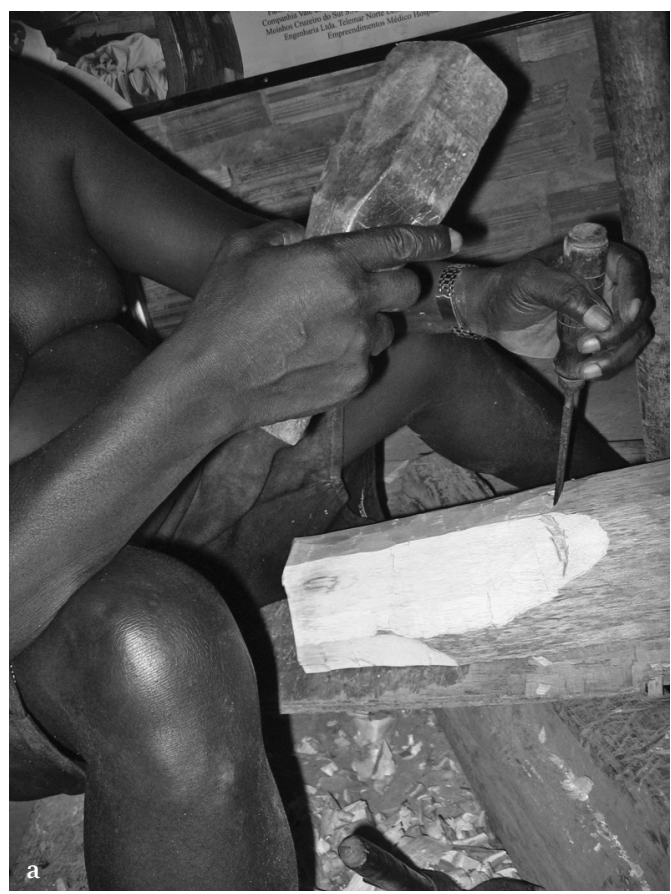

A seguir avanço, do uso maranhense do termo "cazumba", para um uso angolano do termo "casumbi". Destaco o caso da poesia de Viriato da Cruz.
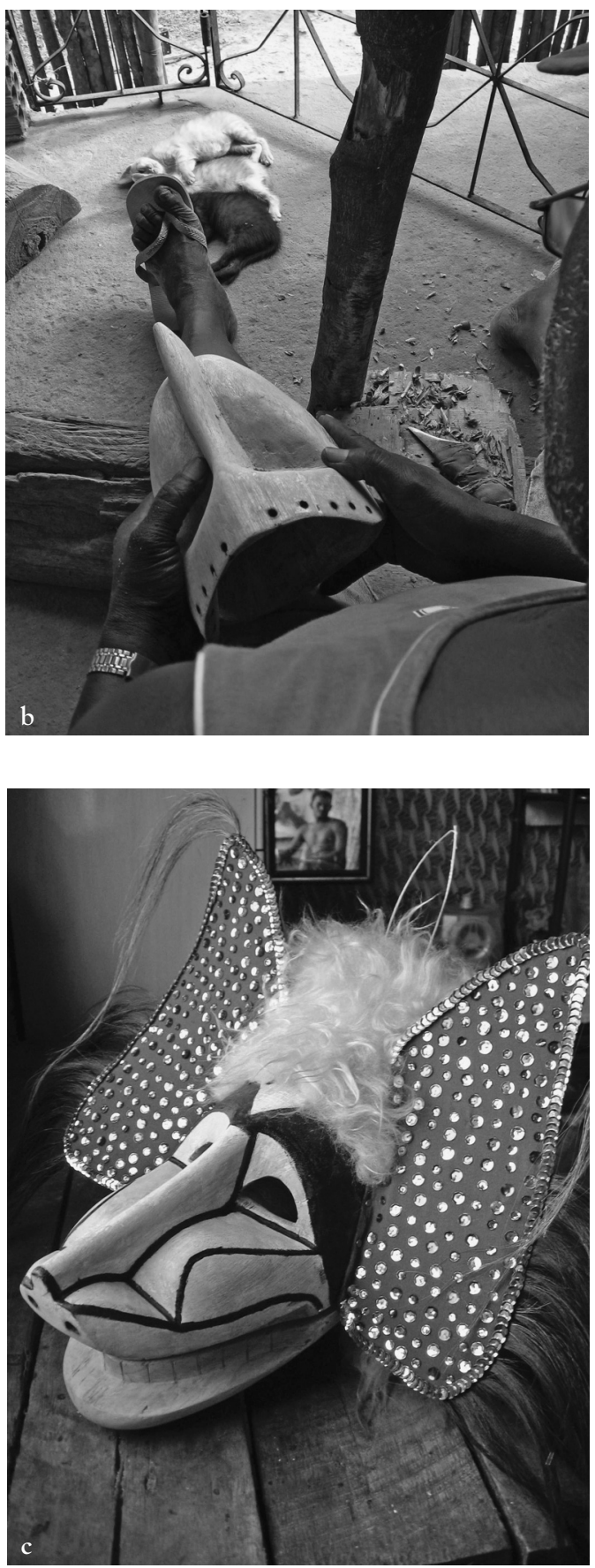

Foto 1a, 1b, 1c. Abel Teixeira entalha "careta” de cazumba, São Luis-MA 2004, bairro do Coroadinho. 


\section{Poema "Serão de Menino"}

(Viriato da Cruz, Angola, década de 1950)

Publicado em Antologias de Poesia da casa dos

Estudantes do Império - ACEI 1994

"Na noite morna, escura de breu, enquanto na vasta sanzala do céu, de volta de estrelas, quais fogaréus, os anjos escutam parábolas de santos...

na noite de breu, ao quente da voz de suas avós, meninos se encantam de contos bantus...

"Era uma vez uma corça dona de cabra sem macho...

$$
\begin{aligned}
& \text {...Matreiro, o cágado lento } \\
& \text { tuc... tuc... foi entrando } \\
& \text { para o conselho animal... } \\
& \text { (“ - Tão tarde que ele chegou!') } \\
& \text { Abriu a boca e falou - } \\
& \text { Deu a sentença final: } \\
& \text { '- Não tenham medo da força! } \\
& \text { Se o leão o alheio retém } \\
& \text { - luta ao Mal! Vitória ao Bem! } \\
& \text { tira-se ao leão, dê-se à corça.””. } \\
& \text { Mas quando lá fora } \\
& \text { o vento irado nas frestas chora } \\
& \text { e ramos xuaxalha de altas mulembas } \\
& \text { e portas bambas batem em massembas } \\
& \text { os meninos se apertam de olhos abertos: } \\
& \text { - Eué } \\
& \text { - É casumbi... }
\end{aligned}
$$

E a gente grande bem perto dali feijão descascando para a quitanda a gente grande com gosto ri...

Com gosto ri, porque ela diz que o casumbi males só faz a quem não tem amor, aos mais seres buscam, em negra noite, essa outra voz de casumbi essa outra voz - Felicidade..."
Em Angola, cazumbi é termo presente na literatura, em particular na poesia de referência nacional, do bilinguismo português-quimbundo. O caso da literatura angolana é característico de um afastamento entre a escrita em português das cidades e as oralidades bantas das regiões do interior, um afastamento que foi sendo vencido.

Para entender o contexto de produção do poema, é preciso olhar para a década de 50 como periodo de balanço da literatura angolana. A partir dessa época ficava mais disseminado o ideal de usar o português apenas como lingua, para expressar questões culturais africanas, que diziam respeito a diversas etnias falantes das linguas bantas. "Casumbi" aqui está apropriado do quimbundo, lingua comum às comunidades da região de Luanda, a capital. Já entre falantes de umbundo, no centro e sul do país, diz-se cadjumbili, para designar um fantasma, uma aparição ou vocalização temivel que é relatada e se relaciona de alguma maneira com algum falecido mais ou menos conhecido.

No poema a figura temivel vem situada na sequência do contar de histórias, mas não surge como personagem de um conto. Surge, isto, sim, do comentário das crianças, ao ouvirem o som do vento nas árvores. Desse modo, o contar do conto pelas avós, com personagens animais, instaura uma atmosfera da ficção, que em seguida recebe a contribuição das próprias crianças, amedrontadas pelo que creem ser o som de algum cazumbi. Portanto, passa-se do universo ficcional do conto para um universo que Sega Touré chama de "imaginário de crenças", importante de ser comentado. Esse imaginário de crenças, usualmente estudado pela antropologia, é bastante familiar à literatura oral, e fornece temas narrativos que a literatura dita "culta" se habituou a re-continuar.

É essa preocupação com as fontes orais que se erguia com força determinante naquele momento da literatura angolana. Aqueles poetas, ao passarem pela vivência da Casa dos Estudantes do Império em Portugal, viam-se como diferentes, como africanos, 
fossem ou não negros na pele. É o caso de Viriato da Cruz. Sua produção, nesse momento, ao re-visitar as histórias contadas pelas avós nos serões da infância, quer reencontrar os falares quimbundos dessas mesmas avós, e com eles uma cultura própria, banto-africana.

É sintomático o abrandamento, pode-se dizer, do conceito etnolinguístico de cazumbi até uma visão nostálgica que, no entanto, não deixa de mobilizar e causar transformação. É assim que os adultos do poema adicionam ao conceito de temor, provocado nas crianças, uma contrapartida positiva do "casumbi":

$$
\begin{aligned}
& \text { “o casumbi males só faz/ } \\
& \text { a quem não tem amor..." } \\
& \text { e conclui-se o poema imaginando } \\
& \text { "essa outra voz de casumbi } \\
& \text { essa outra voz - Felicidade..." }
\end{aligned}
$$

Aí está uma construção poética que tange possivelmente à reaproximação com valores culturais africanos, em diálogo cifrado que evita confrontar abertamente a dominação colonial portuguesa da época. Pode-se entender a "outra voz de casumbi” num plano político, como proposta de remover o teor negativo que a cultura dominante realçou, e assim entender "quem não tem amor" como sendo os colonialistas portugueses e os angolanos "assimilados". Nessa perspectiva, é a eles que os cazumbis deveriam assustar, como às crianças, mas não aos próprios africanos adultos.

Esse papel monstruoso dos cazumbis na oralidade angolana, que o poema quer aproveitar, pode ser comparado ao mistério narrativo envolvendo sempre os cazumbas maranhenses na dança: serão eles adversários

\section{Tradução do francês \\ Tive medo do aspecto temido \\ Eu partia com vocês \\ Tive medo do aspecto temido \\ Máscaras, eu partia com vocês \\ Goro-mine, eu partia com vocês \\ Tive medo do aspecto temido}

ou aliados do boizinho de veludo? Essa pergunta se extrapola, na participação lúdica com o Bumba-meu-boi maranhense, para um questionamento sobre os personagens vaqueiros e o personagem Amo do boi. Vistos dessa ótica do confronto, serão eles proprietários justos, se vão laçar o boi e leválo ao mourão? Vale lembrar que na oralidade o auto popular com o boi recebe o nome de "matança". Portanto, se os cazumbas desaparecessem com o boi, após a disputa encenada com os vaqueiros, estariam virtualmente salvando-o do sacrifício.

Aqui o que mais vale é chegar a essas perguntas, que não têm resposta única e que concedem verossimilhanças conforme a participação do "brincante" de Boi, ano a ano.

\section{Giru-banu-go ninnyia wom - Tive medo do aspecto temido}

(canto dogon de suspensão de luto, da sociedade de máscaras de Pelu, no Mali)

Grupo de Pesquisas de Costumes Dogon - A. Tembene, Bandiagara 1989.

\section{Comentário relacionado:}

"As máscaras manifestam uma força que se impõe: por isso, por ter sentido medo dessa força, não me fui com elas. As máscaras são designadas aqui sob o termo geral de lawa, emprestado do sigi so, mas também sob o nome de goro-mine, que é a máscara do pássaro assim chamado (não-identificado).

O aspecto temivel das máscaras é expresso pelo lema da máscara da gazela (walu): giru-banu toniono, cara temivel pintada de diversas cores".

\author{
Donno-so [Dogon] \\ Giru-banu-go ninnya wom \\ E le ya bem \\ Giru-banu-go ninnya wom \\ Lawa, e le ya bem \\ Goro-mine, e le ya bem \\ Giru-banu-go ninnya bem
}


Sobre a temática da literatura associada a máscaras africanas em contexto, os dogon do Mali têm sido extensamente pesquisados desde a década de 30, quando Marcel Griaule, engenheiro francês com formação posterior em etnologia, publica Masques Dogon (1938). Resultado de expedição ao continente africano com procedimentos colonialistas, $\mathrm{o}$ trabalho gerou criticas e revisões, e pesquisas continuadas por franceses, alemães e espanhóis, entre outros, além dos próprios dogon na atualidade.

A divisão de abordagens entre Letras e Antropologia se abria já no trabalho de Griaule e seguiu com maior produção nesta última disciplina. Hoje um levantamento de estudos sobre os dogon mostra que, em relação à transcrição de cantos relacionados a cada personagem e rito de máscara, Masques Dogon de Griaule e Suspensão de Luto Dogon de Pelu, publicação local do Mali de 1989, são trabalhos mais detalhados.

Desta obra mais recente, cujo titulo completo é A Celebração da Suspensão de Luto os ritos do Dannyi entre os Dogon de Pelu, selecionei a cantiga "Tive medo do aspecto temido" (Giru-banu-go ninnya wom), com a transcrição do original em lingua dogon, a tradução para o francês e os comentários da própria obra.

Os dogon do Mali, no interior do chamado País Dogon, somam perto de 800.000 pessoas. Do planalto seco à falésia, dezenas de aldeias empregam alguma das oito variantes dialetais, como o donno-so e o toro-so. A língua de iniciação às máscaras, o sigi-so, é comum a todo o território dogon, ensinada a grande parte dos homens na adolescência.

A cantiga que transcrevo é de rito púbico, e emprega a variante dialetal donno-so falada na grande aldeia de Pelu, com termos emprestados do sigi-so dos ritos masculinos. O sigi-so é interditado às mulheres, como em tantas linguas de iniciação com máscaras na África, mas apenas no que se refere ao seu uso público. Yves Moñino (1991) verificou, entre os gbaias da República Centro-Africana, situação semelhante, com mais flexibilidade de uso por mulheres. Ali, a lingua labi de iniciação vai adotando novos termos para substituir aqueles que as mulheres já desvendaram e usaram em público. E o processo de criação de novos termos para a lingua especial é também comparável, partindo de metáforas e de línguas vizinhas. Parece que a interdição da elocução pública às mulheres é maior entre os dogon que entre os gbaias. Quanto ao funcionamento da lingua especial, pode-se comparar com o falar da cupópia do Cafundó paulista (Salto de Pirapora-SP), estudada por Margarida Petter (1998) além de Vogt e Fry (1996), pelos termos e frases de lingua externa sobre sintaxe em lingua de base local

No comentário em francês da publicação local dogon, que traduzi, vem a explicação sintética dos versos da cantiga. O sentido básico é: se eu não tivesse medo dos mascarados, seguiria com eles para fora da aldeia ao final do rito, quando retornam para seus locais junto à natureza. Neste caso, retornam às grutas da falésia, onde depositam secretamente as máscaras. Os sepultamentos também são realizados em grutas dessa grande falésia. Seguir com as máscaras deixando a aldeia significa, nesse contexto de simbologia, virtualmente deixar esta vida. Isto porque os cortejos e danças com máscaras, por portadores iniciados, ocorrem em rito funerário, quando vêm dançar sobre o teto da casa de um idoso bem conhecido que tenha falecido, e em rito de suspensão de luto, homenagem coletiva aos falecidos recentes, a cada ano ou até três anos transcorridos. Coincidem aspectos desses ritos de suspensão de luto, contexto da cantiga selecionada, com o rito quarup de povos indigenas brasileiros.

Eis então que os mascarados, entre os dogon, participam da narrativa socializada da morte e da passagem da alma, e causam temor pela ação como destinadores nessas narrativas sociais. No entanto não são os causadores dessa morte, são condutores de cortejo e propiciadores de alivio aos familiares, por seu papel nos ideários de crenças. Porque nesses procedimentos dramatizados assentam as almas e fixam ritos de rememorar, que se podem entender como dar continuidade à vivência terrena em situações propícias de contato e participação. 
Pode-se dizer que as máscaras dão marcadores materiais que ajudam a organizar a memória imaterial. Esse é o papel, fazendo aqui uma associação, dos livros nas sociedades em que predomina o acesso literário ao conhecimento. No entanto, vista de perto, a memorização e fixação de conhecimentos pelo uso das máscaras é engajada, irredutivel, com grande poder de re-encenar as histórias e estabelecer referências das literaturas orais.

4. A categoria narrativa do "monstruoso" (N. Sega Touré), chave teórica do campo da Literatura Oral

No trabalho Langage et Cultures Africaines Essais réunis et présentés par Geneviéve CalameGriaule, publicado em 1977, duas grandes linhas de abordagem se firmaram: a de "Lingua e visão de mundo", subdividida em

1. Taxonomias e sistemas de relações e

2. Campos semânticos,

e a de "Literatura Oral", subdividida em

1. Literatura oral e sociedade e

2. Estilistica e níveis de linguagem.

Sobre máscaras e termos associados, vem situado na primeira parte um texto denso de Marie-Paule Ferry com o titulo "Les noms des hommes et des masques chez les Basari du Sénégal oriental”. Ai se entende, mais uma vez, a referência às máscaras como recorrente entre linguagens e linguas de todo o Niger-Congo.

De 1977 até hoje essas mesmas linhas de pesquisa se desdobraram. Formou-se o laboratório LLACAN (Langage, Langues et Cultures d'Afrique Noire) do CNRS (Centro Nacional de Pesquisa Cientifica francês) com vários dos pesquisadores reunidos naquele trabalho apresentado por Geneviéve Calame-Griaule. Davam prosseguimento aos estudos de literaturas orais, par-e-passo com as descrições das linguas africanas. Jean Derive era no grupo um autor com formação estrita em literatura, que passou a orientar doutorandos africanos e africanistas interessados, especialmente dos paises francófonos.
Assim, em 2005 surgiu uma obra coletiva em homenagem a Jean Derive, com pesquisadores orientados por ele: Approches littéraires de l'oralité africaine, organizada por Ursula Baumgardt e Françoise Ugochukwu (Paris, Karthala 2005). E nessa obra vem, no cap. 5 , "Qui est le monitor: Sur les traces du mâitreinitiateur dans quelques contes wolof" (N. Sega Touré), uma chave conceitual que passei a incorporar, porque operacionaliza minha comparação.

De fato, propus pesquisa de comparação entre manifestações aparentemente distanciadas no tempo e espaço, na natureza literária ou oral e nas manifestações sociais, dadas como profanas ou sagradas, no Brasil e na África. Só no campo da literatura se justificaria, à primeira vista, a comparação entre certos versos, cantigas, personagens e máscaras do Maranhão, Angola, Nigéria ${ }^{8}$ e Mali, mas me pareceu necessário e viável. Aqui o terreno de base é precisamente o dos estudos de Literatura Oral. Os terrenos adjacentes, por sua vez, são os da etnomusicologia, antropologia, literaturas locais em lingua portuguesa, francesa e inglesa, e ainda os de história e geografia.

A comparação que proponho se delimita: conjuga uma prática de literatura comparada, entre exemplos orais e literários, com um enfoque dos sujeitos afro-brasileiros e africanos, em viés étnico-social.

O que Sega Touré apresenta como categoria recorrente, na oralidade senegalesa e guineense, ou seja, o monitor com suas figurações do "monstruoso", permite reaproximar gêneros orais e poéticos que se haviam isolado em disciplinas, os primeiros para o lado da antropologia, e esses últimos, para o lado da literatura.

O monitor ou mestre iniciador e suas figurações do "monstruoso" se dão a entender como categorias recorrentes, em cantos, contos e outros gêneros orais que revigoram o

(8) Aqui não trago ainda exemplo beninense-nigeriano para a comparação, caso de cantos de máscaras de sociedades Geledé. 
entendimento dos papéis sociais das literaturas. E os intercâmbios entre os gêneros orais do conto, canção, epopéia e provérbio saltam aos olhos com as comparações, para não falar dos intercâmbios entre literaturas de povos vizinhos.

Monitor foi o termo latino apropriado por Sega Touré, em lugar de mentor, este sim corrente no francês, para designar o papel narrativo do actante que representa o mestreiniciador, apoiador do sujeito, por vezes sob figuração de agressor. Assim, a prova narrativa ou busca identitária dependem de um enfrentamento com o desconhecido, normalmente representado por figuração monstruosa, figuração que mostra algo. Acredito que está ai o fator que faz vincular o entendimento de muitos contos de oralidade àquelas encenações rituais com máscaras: a presença do monstruoso. E assim, a chave teórica usada pela autora senegalesa pode expandir-se de seu campo de literatura e valer para o campo antropológico, apenas entendendo-se a dimensão narrada do conto, a poética dos versos e a dimensão encenada da saída de máscara.

\section{Agradecimentos}

A Margarida Petter (FFLCH-USP/DL/ GELA), que forneceu especialmente Approches littéraires de l'oralité africaine (2005); a Paulette Roulon-Doko e Yves Moñino (Llacan/Cnrs) que co-dirigiram e estimularam; a Denise Dias Barros (USP e Casa das Áfricas), que cedeu A Celebração da Suspensão de Luto - os ritos do Dannyi entre os Dogon de Pelu (1989); a Lisy Salum (MAE-USP), que apresentou Masques Dogons de Griaule (1983 [1938]) e a Tania Alkmin (Unicamp), que cedeu Langage et Cultures Africaines - Essais réunis et présentés par Geneviéve Calame-Griaule (1977).

BUENO, A.C.P. Mask chants in Northeastern Brazil and in Central and West Africa; traces for a comparative analysis. Revista do Museu de Arqueologia e Etnologia, São Paulo, 20: 381-391, 2010.

Abstract: Language data and oral literature data are contrasted here, to focus African and Afro-Brazilian lyrics related to mask characters. I selected one chant from my previous field research in Maranhão state (Northeastern Brazil), a poem from Angola and a chant from the Dogon of Mali. The first is in Brazilian Portuguese with Kimbundu words; the second is in Angolan Portuguese with Kimbundu words; the third is in Dogon language including local Sigi-so initiation language. Linguistic borrowing of the African word cazumba in Brazil is shown (from kimbundo kanzumbi). The coherences in meanings and in narrative details, from both sides of the Atlantic, are consistent and evoke new steps of comparison to be done. The theoretical key of the "monstruous" and "monitor" or initiation master, as used by N. Sega Touré (in Baumgardt \& Ugochukwu 2005), helps establishing this comparison, to link concepts from ethnology, language and literature studies. And detailed notes on the Brazilian example of bumba-boi dance drama in context emphasize local dynamics of oral transmission.

Keywords: Mask chants - Monstruous - Bumba-meu-boi - Cazumba Afro-Brazilian - Kimbundu - Oral tradition music - Dogon. 


\section{Referências bibliográficas}

BARROS, D. D.

2004 Itinerários da loucura em territórios Dogon. São Paulo: Fiocruz/Casa das Áfricas.

BAUMGARDT, U.; UGOCHUKWU, F. (Orgs.)

2005 Approches littéraires de l'oralité africaine. Paris: Ed. Karthala.

BUENO, A.C.P.

2001 Bumba-boi maranhense em São Paulo. São Paulo: Ed. Nankin/Fapesp (livroCD). [Antes dissertação de mestrado. FFLCH-USP 1999].

2006 Palhaços da cara preta: Pai Francisco, Catirina, Mateus e Bastião, parentes de Macunaima nos Bumba-bois e Folias-deReis - MA, PE, MG. Tese de doutorado. FFLCH-USP.

2008 A noção de pseudo-lingua (Y. Moñino 1991) para a cupópia de Cafundó (Salto de Pirapora-SP) e para os cantos de máscara do Boi maranhense. Comunicação ABECS.

CALAME-GRIAULE, G.

1965 Ethnologie et Langage - La parole chez les Dogon. Paris: Gallimard.

1977 Langage et Cultures Africaines - Essais réunis et présentés par Geneviéve CalameGriaule, Paris: Ed. Khartala.

CHATELAIN, $\mathrm{H}$.

1964 Contos populares de Angola : cinquenta contos em quimbundo. Lisboa : AgenciaGeral do Ultramar [1894].
DOGON, GROUPE DE RECHERCHE DE COUTUMES (TEMBELY, A.; KASSOGUE, D.; KERVRAN, M.)

1989 La célebration de la lévée de deuil - Les rites du dannyi chez les dogons de Pelu. Bandiagara, Mali.

GRIAULE, M.

1983 Masques Dogons. Paris. Institut d'Ethnologie [1938].

MAZZILLO, M.

2005 Careta de cazumba. Rio de Janeiro: Caburé/Petrobrás.

MOÑINO,Y.

1991 Les langues spéciales sont-elles des langues? La notion de pseudo-langue à travers l'exemple d'une 'langue d'initiation' d'Afrique Centrale. Separatas Langage et Societé. Paris, Maison Sciences de l'Homme.

2006 Les rôles du substrat dans les créoles et les langues secrètes: le cas du palenquero, créole espagnol de Colombie. In: Gadelii, K.; Zribi-Hertz, A. (Orgs.) Grammaires créoles et grammaire comparative. Saint-Denis, Presses Universitaires de Vincennes: 49-72.

\section{PETTER, M.M.T.}

1998 Linguas especiais, linguas secretas: na África e no Brasil. Revista da ANPOLL,4, São Paulo, Humanitas, USP: 185-202.

VOGT, C.; FRY, P.

1996 Cafundó - A África no Brasil. Campinas: Ed. Unicamp/ Cia. das Letras. 